\title{
Prevalence of Thyroid Dysfunction in Systemic Lupus Erythematosus of Bahraini Patients
}

\author{
Ola A. Moneim ElSegai ${ }^{(*)} M S c, P h D$, Eman M. Farid $M S c, M D^{(*)}$, \\ Reda A. Ebrahim ${ }^{(\#)} M R C P, U K$ \\ Departments of Medical Biochemistry ${ }^{(*)}$, Clinical Pathology ${ }^{(* *)}$ \\ and Internal Medicine ${ }^{(\#)}$, Salmanya Medical Complex, \\ Ministry of Health, Kingdom of Bahrain
}

\begin{abstract}
Background: Controversy about the prevalence of thyroid dysfunction in systemic lupus erythematosus (SLE) patients has been reported. As no previous study evaluated thyroid status in SLE Bahraini (BSLE) patients, so, the current study aimed to evaluate the prevalence of thyroid dysfunction among those patients compared to an age and sex matched healthy control group. Methods: Retrospective laboratory data of the thyroid function in forty-three SLE Bahraini patients who were recently diagnosed and fulfilling four criteria of the American College of Rheumatology (ACR) criteria were evaluated. One hundred-fifty matched healthy controls were selected from the general population laboratory records for thyroid function screening or routine annual checkup. Results: The overall thyroid dysfunction among BSLE patients was $32.5 \%$ VS $12.6 \%$ in the control group $(P<0.002)$. The most prevalent thyroid dysfunction in SLE patient was the subclinical form compared to the control group, the prevalence of subclinical hypothyroidism was significantly higher $(P<0.002)$ whereas, subclinical hyperthyroidism was insignificantly different. Laboratory data did not reveal any overt thyroid dysfunction among patients and controls. Conclusion: Subclinical hypothyroidism was significantly higher among BSLE patients than in healthy controls. Physician during follow up of SLE patients should be alert for the development of overt thyroid dysfunction in high risk group especially the female gender.
\end{abstract}

Keywords: Subclinical hypothyroidism - subclinical hyperthyroidism - thyroid dysfunction - systemic lupus erythematosus. Bahraini.

\section{INTRODUCTION}

Systemic Lupus Erythematosus (SLE) is a multisystemic chronic autoimmune disease. Thyroid gland may be one of the target organs affected and the prevalence of thyroid disease in lupus patients is controversial. A number of studies have suggested that thyroid disease is more common in SLE patients than in the general population. ${ }^{(1,2,3,4)}$. Other reports concluded that there is no clear association between the two diseases. ${ }^{(5)}$. No previous study has reported the prevalence of thyroid dysfunction among SLE Bahraini (BSLE) patients. Thus, the aim of the present study is to assess the prevalence of thyroid dysfunction in 
those patients compared with a control group.

\section{MATERIALS \& METHODS}

The current, case control, retrospective study was performed on randomly selected forty-three BSLE patients attending the SMC Rheumatology Clinic, Bahrain, during the period from the $1^{\text {st }}$ of December 2012 to $31^{\text {st }}$ May 2013. All patients met four or more of the eleven revised classification criteria of the American College of Rheumatology (ACR). The study was approved by the Ethical Committee of the Hospital.

The control group included one hundred-fifty healthy subjects of matched sex and age. They were selected from laboratory records for general population attending SMC clinic for routine annual checkup or screening of thyroid function.

Free thyroxine (FT4) was
measured

electrochemilumenescence

immunoassay "ECLIA" for use on Elyces and Cobas-e immunoassay analyzer. The lowest detection limit (sensitivity) was $0.3 \mathrm{pmol} / \mathrm{L}$. Thyrotropin hormone (TSH) was measured using electrochemilumenescence

immunoassay "ECLIA" for use on Roche Elyces analyzer. The sensitivity was $0.005 \mathrm{uIU} / \mathrm{L}$. The reference range for TSH and FT4 were $\quad 0.5-5 \mathrm{uIU} / \mathrm{L} \& 5.0-25 \mathrm{pmol} / \mathrm{L}$ respectively. Patients with TSH level above the reference range with normal FT4 were diagnosed as subclinical hypothyroidism, whereas, subclinical hyperthyroidism was defined as diminished TSH level $<0.25 \mathrm{uIU} / \mathrm{L}$ with FT4 within the reference range.

\section{Statistical Analysis:}

Statistical analysis was performed using SPSS version 20 for window. Independent sample t-test was used to compare means of continuous variables. Chi-Square test $\left(\chi^{2}\right)$ is used to compare the frequency of the variables for two groups. Mann Whitney and $\mathrm{K}$ independent test (Kruskal Wallis) used to compare differences between subclasses of the two groups. Differences were considered significant with a probability of $\mathrm{P}<0.05$.

\section{RESULTS}

The present study included fortythree SLE patients; their mean age was $37.5 \pm 11.5$ years (14-60years), forty were females $(93 \%)$ and three were males $(7 \%)$. In the control group the mean age was $35.7 \pm 12.3$ among them 142 were females $(94.6 \%)$ and 8 were males $(5.4 \%)$.

The overall thyroid dysfunction was $32.5 \%(14 / 43)$ in BSLE patients and $12.6 \%(19 / 150)$ in the control group ( $\mathrm{P}<0.002)$. The most prevalent thyroid dysfunction in BSLE patients was subclinical hypothyroidism, $(10 / 43)$ patients $(23.25 \%)$ whereas, in the control group subclinical hypothyroidism was present in $(12 / 150)$ patients $(8 \%),(\mathrm{P}<0.002)$. On the other hand, although subclinical hyperthyroidism was statistically insignificant in patients (4/43 -9.3\%) Vs the corresponding group in control (7/150-4.7\%): $\mathrm{P}>0.05)$, and serum FT4 was within the reference range, it was significantly higher than in control $(\mathrm{P}<0.01)$. 
Thyroid dysfunction was more prevalent in females as the three SLE males included in the study had euthyroid function $(\mathrm{P}<0.0001)$. In addition, out of the ten subclinical hypothyroidism female patients, four were under the age of 30 years. Age of cases of subclinical hyperthyroidism was above 30 years.
Statistical analysis revealed no significant correlation with age $(\mathrm{P}>0.05)$.

The study also revealed that none of the patients or controls was diagnosed according to the laboratory data as manifest or overthypo or hyperthyroidism.

Table (1): Comparison between Demographic data of SLE patients \& control

\begin{tabular}{|l|l|l|l|}
\hline & SLE patient & Control & P value \\
\hline Age & $37.5+11.5(14-60)$ & $35.7+12.3(11-65)$ & $\mathrm{P}>0.05$ \\
\hline Female No & $40(93 \%)$ & $142(94.6 \%)$ & \multirow{2}{*}{$\mathrm{P}>0.05$} \\
\hline Male No & $3(7 \%)$ & $8(5.4 \%)$ & \\
\hline
\end{tabular}

Table (2): Thyroid status in SLE patients \& Control

\begin{tabular}{|c|c|c|c|c|c|}
\hline \multirow{2}{*}{ No of cases } & \multicolumn{2}{|l|}{ Patients } & \multicolumn{2}{|l|}{ Control } & \multirow[t]{2}{*}{ P value } \\
\hline & Number & $\%$ & Number & $\%$ & \\
\hline Overall thyroid dysfunction & 14 & 32.5 & 19 & 12.6 & $\mathrm{P}<0.002^{*}$ \\
\hline Euthyroid & 29 & 67.4 & 131 & 87.3 & $\mathrm{P}>0.05$ \\
\hline Subclinical hypothyroidism & 10 & 23.25 & 12 & 8 & $\mathrm{P}<0.002^{*}$ \\
\hline Subclinical hyperthyroidism & 4 & 9.3 & 7 & 4.7 & $\mathrm{P}>0.05$ \\
\hline
\end{tabular}

* Indicates significance difference between patient \& control

$\mathrm{Eu}=$ euthyroid. $\mathrm{SHT}=$ Subclinical hypothyroidism

$\mathrm{SH}+=$ Subclinical hyperthyroidism

Table (3) Mean + SD of TSH \& FT4 levels in BSLE patients \& Control

\begin{tabular}{|c|c|c|c|c|c|c|c|c|}
\hline & \multicolumn{4}{|l|}{ SLE } & \multicolumn{4}{|c|}{ Control } \\
\hline & All & $\mathrm{Eu}$ & SHT & $\mathrm{SH}+$ & All & $\mathrm{Eu}$ & SHT & $\mathrm{SH}+$ \\
\hline TSH & $\begin{array}{l}3.4 \\
+3.6 \\
\end{array}$ & $\begin{array}{l}2.08 \\
+0.83 \\
\end{array}$ & $\begin{array}{l}8.68 \\
+4.05 \\
\end{array}$ & $\begin{array}{l}0.175 \\
+0.17 \\
\end{array}$ & $\begin{array}{l}2.6 \\
+1.9 \\
\end{array}$ & $\begin{array}{l}2.32 \\
+1.19 \\
\end{array}$ & $\begin{array}{l}7.34 \\
+2.44 \\
\end{array}$ & $\begin{array}{l}0.23 \\
+0.15 \\
\end{array}$ \\
\hline$P$ value & $\mathrm{P}<0.01 *$ & $\mathrm{P}>0.05$ & $\mathrm{P}>0.05$ & $\mathrm{P}>0.05$ & & & & \\
\hline FT4 & $\begin{array}{r}14.5 \\
+3.2 \\
\end{array}$ & $\begin{array}{r}14.18 \\
+2.39 \\
\end{array}$ & $\begin{array}{l}14.96 \\
+3.47 \\
\end{array}$ & $\begin{array}{l}18.4 \\
+5.18 \\
\end{array}$ & $\begin{array}{l}11.42 \\
+2.59 \\
\end{array}$ & $\begin{array}{l}11.42 \\
+2.39 \\
\end{array}$ & $\begin{array}{l}13.3 \\
+1.42 \\
\end{array}$ & $\begin{array}{l}8.67 \\
+4.5\end{array}$ \\
\hline $\mathrm{P}$ value & $\mathrm{P}>0.05$ & $\mathrm{P}>0.05$ & $\mathrm{P}>0.05$ & $\mathrm{P}<0.01^{*}$ & & & & \\
\hline
\end{tabular}

$*$ Indicates significance difference between patient \& control

$\mathrm{Eu}=$ euthyroid. SHT $=$ Subclinical hypothyroidism

$\mathrm{SH}+=$ Subclinical hyperthyroidism 


\section{DISCUSSION}

The results of the present study revealed significantly higher prevalence of thyroid dysfunction in BSLE patients than the control group $(32.5 \%$ VS $12.6 \%, \mathrm{P}<0.002)$. This come in agreement with other studies done in the same geographic area including China ${ }^{(1)}$, Southeast $\operatorname{Iran}^{(6)}$, Egypt ${ }^{(7)}$ which reported that the overall prevalence of thyroid dysfunction in SLE patients was $22.2 \%, 24.1 \%$ and $50 \%$ respectively. Furthermore, the present study revealed a predominance of the subclinical form of thyroid dysfunction with significant prevalence of subclinical hypothyroidism $(\mathrm{P}<0.002)$. The figure in our study was $23.25 \mathrm{vs} 9.3 \%$ for subclinical hypothyroidism and subclinical hyperthyroidism respectively. These figures are in the higher ranges reported by other studies. Variable figures reported in the literature for the prevalence of hypothyroidism and hyperthyroidism ranging from 3.9 to $39 \%$ and 0 to $10.9 \%$, respectively. ${ }^{(1,2,3,4)}$. These wide variations could be contributed to different sensitivities of the assay methods, the sample size included in the different studies, or racial prevalence of thyroid disease among the studied groups.

On the other hand, some other studies reported no difference in thyroid function between patients and controls and concluded that evaluation of thyroid function should be measured only in patients with clinical manifestations of hypo- or hyperthyroidism. ${ }^{(5)}$
Regarding overt thyroid dysfunction, Chan et al., reported that $4.3 \%$ of SLE patients had overt hypothyroidism ${ }^{(8)}$. Mader et al., as well, reported $11.6 \%$ overt hypothyroid of SLE patients compared to $1.9 \%$ in the control group $^{(9)}$. In contrast, Goh and Wang $^{(10)}$ reported that among Malaysian SLE patients, there was a higher incidence of thyrotoxicosis among SLE patients than in the general population and attributed the thyroid disorder to be a result of antithyroid activity of one of the antibodies produced in SLE. ${ }^{(10)}$.

The absence of laboratory overt thyroid dysfunction (hypo or hyperthyroidism) in the present study may be attributed to the limited numbers of SLE patients evaluated or the absence of other associated autoimmune disease or antithyroid antibodies (the latter was not evaluated in the present study). However, since SLE is a systemic autoimmune disease that can affect any target organ it is interesting to speculate that the thyroid disorders are the result of antithyroid antibodies produced in SLE ${ }^{(11)}$ or autoimmunity and antithyroid antibodies should be evaluated in those patients especially antithyroperoxidase antibodies (TPO$\mathrm{Ab})$ in females ${ }^{(\mathbf{8}, 10)}$.

Comparing the means of TSH \& FT4 levels in both groups, FT4 was only significantly higher in BSLE subclinical hyperthyroid patients versus control group although it was within the reference range $(\mathrm{P}<0.001)$. This could be explained on the basis that thyrotoxicosis could preceed the incidence of autoimmune disorders and this may prevail the importance of 
measuring antithyroid antibodies in those patients ${ }^{(12,13)}$.

Taking age and gender in consideration, Pyne and Isenberg reported insignificant difference in the prevalence of thyroid disease in SLE patients compared with age and sex matched control ${ }^{(2)}$. Costa et al. reported that the prevalence of thyroid disorder is more prevalent in adult than in juveniles $\mathrm{SLE}^{\left({ }^{(14)} \text {. These }\right.}$ results also confirmed several previous reports which showed that overt hypothyroidism rarely develops below the age of 35 years and verified the risk factors for progression of subclinical hypothyroidism to overt hypothyroidism as age, female gender and raised thyroperoxidase antibodies ${ }^{(8,15,16,17)}$. The results of our study revealed significant association between female gender with thyroid dysfunction, whereas insignificantly association of age was found which could be attributed to the small number of patient included in the study or overt thyroid dysfunction may develop in older age than those included in our study ${ }^{(\mathbf{8 , 1 5})}$.

It could be concluded that subclinical form of thyroid dysfunction was more frequent in BSLE patients than the healthy control group. It is recommend not only screening the thyroid function at the onset of the disease in new cases of SLE patients, but also, evaluating the level of antithyroid antibodies in those patients because of the common autoimmune nature of both diseases. Furthermore, physicians caring for SLE patients should remain alert to the possible development of overt thyroid dysfunction during follow up taking the risk factors in consideration.

\section{REFERENCES}

1. Weetman AP; Walport

MJ(1987): Association of autoimmune thyroiditis with systemic lupus erythematosus. Br. J. Rheumatol., 26(5):359-61.

2. Pyne D, Isenberg DA (2002): Autoimmune thyroid disease in systemic lupus erythematosus. Ann. Rheum. Dis., 61(1):70-2

3. Al-Saleh JA, El-Sayed ME, Jassim V, Mohamed N. Khan N (2008): Hypothyroidism determines the clinical and immunological manifestations of Arabs with lupus. Lupus 17(3):215-20

4. Becker KL, Ferguson RH, McConahey WM.(1983): The connective tissue diseases and symptoms associated with Hashimoto's thyroiditis. N. Engl. J. Med., 268: 277-80.

5. Mulhern LM, Masi AT and Sulman LE (1966): Hashimoto's disease: A search for associated disorders in 170 clinically detected cases. Lancet 2(7462) 508-511.

6. Zakeri Z, Sandooghi M. (2010): Thyroid Disorder in Systemic Lupus Erythematosus Patients in Southeast Iran. Shiraz E Medical Journal. 11(1) 1-6.

7. El-Sherif WT, EIGendi SS, Ashmawy MM, Ahmed HM and Salama MM (2004): Thyroid disorders and auto antibodies in systemic lupus erythematosus and rheumatoid 
arthritis patients. Egypt. J. Immunol., 11(2): 81-90.

8. Chan AT, Al-Saffar Z, Bucknall RC (2001): Thyroid disease in systemic lupus erythematosus and rheumatoid arthritis. Rheumatology 40(3):353-354.

9. Mader R, Mishail S, Adawi M, Lavi I, Luboshitzky R..(2007): Thyroid dysfunction in systemic lupus erythematosus (SLE): relation to disease activity. Clin. Rheumatol., 26(11):1891 - 4

10. Goh KL and Wang F. (1986): Thyroid disorders in systemic lupus erythematosus. Ann. Rheum. Dis., 45(7): 579-583.

11. Hughes GRV (1984): Autoantibodies in lupus and its variant: Experience in 1000 patients. Br. Med. J., 289(6441):339-42.

12. Thomas RD, Croft DN (1974): Thyrotoxicosis and giant-cell arteritis. Br. Med. J., 2(5916):408-9.

13. Simone A., Ana P, Ricardo N, Lilian C (2009): Prevalence of thyroid dysfunction in systemic lupus erythematosus. J. Clin. Rheum., 15(3), 117-119.

14. Costa LP, Bonfa E, Martinago CD, de Oliveira RM, Carvalho
JLF and Pereira RM (2009): Juvenile onset systemic lupus erythematosus thyroid dysfunction: a subgroup with mild disease?. J. autoimmunity. 33(2): 121-124.

15. Vanderpump MPJ, Tunbridge WMG, French JM, Appleton D, Bates D, Clark F,Grimley Evans J, Hasan DM, Rodgers H, Tunbridge FT \& Young ET (1995): The incidence of thyroid disorders in the community: a twenty-year follow up of the Wickham survey. Clin. Endocrinol. (Pxford) 26(1):88 68.

16. Eberhad BA, laxer RM, Eddy AA, Silverman ED (1991): Presence of thyroid abnormalities in children with systemic lupus erythematosus. J. Pediatric., 119(2):277-9.

17. Ronchezel MV, Len CA, Spinola E Castro A, Sacchetti S, Lourenzi VM, Ajzen S, Tufik S, Hilário MO. (2001): Thyroid function and serum prolactin levels in patients with juvenile systemic lupus erythematosus. J. pediatr. Endocrinol. Metab., 14(2):165-9. 


\section{معدل حدوث اضرابات وظيفة الغدة الدرقية بين مرضى البحرين المصسابين}

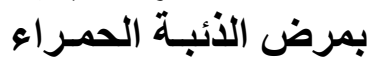

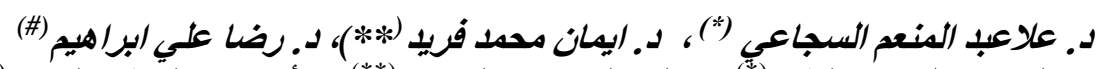

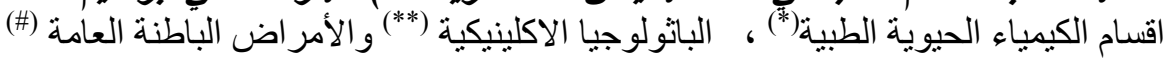

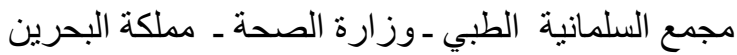

الأهداف: تقييم وظيفة الغدة الدرقية في مرضى الذئبة الحمر فاء في البحرينيين مقارنة بمجموعة ضـابطة من

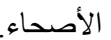

الطريقة: أجريت هذه الدراسة الاسترجاعية بمختبر ات مجمع السلمانية الطبي بدولة البحرين. شملت الدراسة

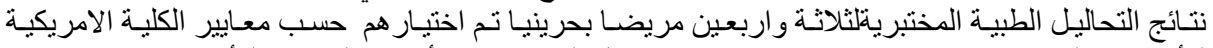

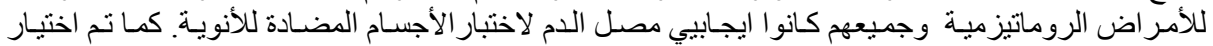
المجموعة الضابطة من خلال سجلات المختبر اليومية للمسح الروتيني لوظيفة الغدة الدرقية أو الفحص الطبي لإني

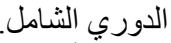

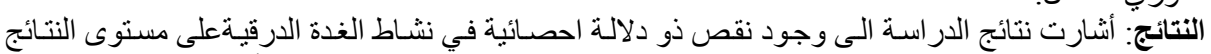

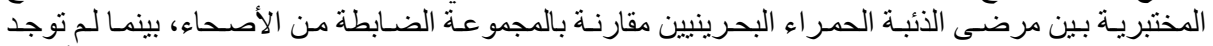

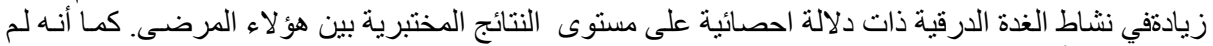

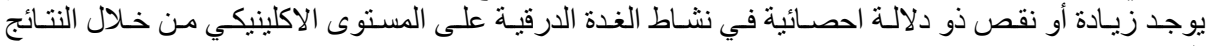
الالمختبرية.

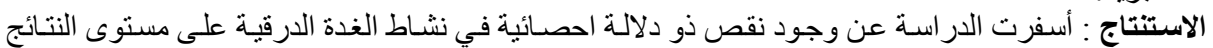

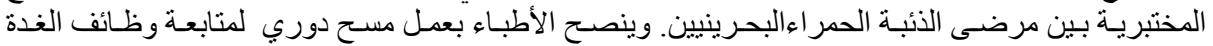

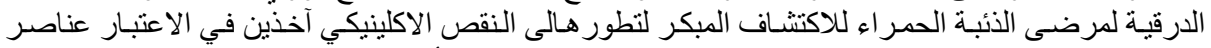

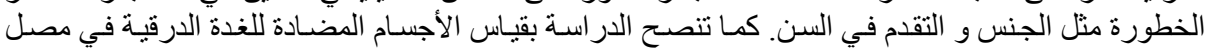

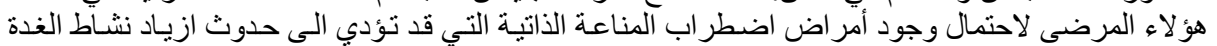

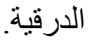


